\title{
Association between anxiety disorder and the extent of ischemia observed in cardiac syndrome $\mathrm{X}$
}

\author{
I.A.C. Vermeltfoort, $M D,{ }^{a}$ P.G.H.M. Raijmakers, $M D, P h D,{ }^{a}$ D.A.M. Odekerken, \\ $M D,{ }^{b}$ A.F.M. Kuijper, MD, PhD, ${ }^{b}$ A. Zwijnenburg, $M D, P h D,{ }^{c}$ and G.J.J. Teule, $M D$, \\ $\mathrm{PhD}^{\mathrm{d}}$
}

Background. A possible link between the heart and brain has been reported for cardiac syndrome $X$. Anxiety disorder could be a pathophysiological mechanism for this cardiac chest pain. To the authors' knowledge, a quantitative analysis correlating anxiety with the extent of ischemia has not been done.

Methods and Results. In this pilot study, we evaluated 20 patients with typical chest pain and completely normal coronary angiograms. These patients were screened with the State Scale and Trait Scale of the State-Trait Anxiety Inventory (STAI). All patients underwent myocardial perfusion scintigraphic imaging. The scintigrams were scored by three experienced readers having no knowledge of the STAI screening results. Patients with a low trait anxiety had significantly less ischemic segments on the myocardial perfusion imaging than patients with a high trait anxiety $(1.8 \pm 1.9$ vs $3.5 \pm 0.6, P<.05)$. For state anxiety, no significant differences could be found.

Conclusion. Cardiac syndrome $X$ patients with high trait anxiety are at risk of having more ischemia. ( $\mathrm{J}$ Nucl Cardiol 2009;16:405-10.)

Key Words: Myocardial perfusion imaging $\cdot$ SPECT $\bullet$ coronary artery disease $\bullet$ ischemia $•$ myocardial

\section{INTRODUCTION}

About $20 \%$ of patients with anginal chest pain have normal coronary angiograms. ${ }^{1,2}$ The term "cardiac syndrome X" (CSX) was introduced to describe these patients. ${ }^{3,4}$ A subgroup of these patients has objective signs of ischemia, such as the classic downsloping ST-segment depression on exercise testing and/or a reversible defect detected by myocardial single-photon emission computed tomography (SPECT) ${ }^{5-9}$

From the Department of Nuclear Medicine \& PET Research, ${ }^{a}$ VU University Medical Centre, Amsterdam, The Netherlands; Department of Cardiology, ${ }^{\mathrm{b}}$ and Department of Nuclear Medicine, ${ }^{\mathrm{c}}$ Spaarne Hospital, Hoofddorp, The Netherlands and Department of Nuclear Medicine \& PET, ${ }^{\mathrm{d}}$ Maastricht University Medical Center, Maastricht, The Netherlands.

Received for publication Mar 13, 2008; final revision accepted Nov 4, 2008.

Reprint requests: I.A.C. Vermeltfoort, MD, Department of Nuclear Medicine \& PET Research, VU University Medical Center, Amsterdam, de Boelelaan 1117, 1007 MB Amsterdam, The Netherlands; i.vermeltfoort@vumc.nl.

$1071-3581 / \$ 34.00$

Copyright $(\odot 2008$ The Authors(s). This article is published with open access at Springerlink.com.

doi:10.1007/s12350-008-9032-2
The pathogenesis of CSX remains uncertain. Two mechanisms have been proposed: ischemia caused by coronary microvascular dysfunction, and enhanced cardiac pain sensitivity ("sensitive heart" syndrome). ${ }^{10}$

Several studies found abnormalities consistent with ischemia in patients with syndrome $\mathrm{X}$ using scintigraphic myocardial perfusion imaging, ${ }^{5-9}$ thermodilution, ${ }^{11}$ nuclear magnetic resonance spectroscopy, ${ }^{12}$ intracoronary acetylcholine, ${ }^{13,14}$ atrial pacing, ${ }^{15}$ and cardiac magnetic resonance (CMR) imaging. ${ }^{16,17}$ These CMR studies support the hypothesis of microvascular ischemia in CSX patients. There are also PET studies demonstrating a reduced coronary flow reserve in CSX patients. ${ }^{18-20}$ On the other hand, a recent CMR study found no impairment of subendocardial blood flow response in CSX patients, ${ }^{21}$ and a PET study by Rosen et al showed no differences in myocardial blood flow between CSX patients and healthy controls. ${ }^{22}$

In the last few years, attention has been paid to the effect of psychological factors on coronary artery disease (e.g., atherosclerosis) and cardiac neural mechanisms. ${ }^{23}$ Previous work identified the importance of impaired myocardial blood flow, particularly in the microvascular bed, in relation to mental stress, ${ }^{24,25}$ and the phenomenon 
of endothelial dysfunction induced by mental stress has been described in $\mathrm{CSX}^{26}{ }^{26}$ Furthermore, CSX patients have significantly higher levels of anxiety. ${ }^{27}$

Owing to the conflicting data regarding ischemia in CSX patients, and also the possible role of anxiety, we performed a pilot study to measure the extent of ischemia and anxiety levels in a group of CSX patients.

\section{METHODS}

\section{Patients}

The pilot study population consisted of 20 patients from the outpatient clinic of the cardiology department in a general hospital (February 2004-September 2004). All patients exhibited typical chest pain, positive exercise stress testing $(0.1 \mathrm{mV}$ horizontal or downsloping ST-segment depression of $80 \mathrm{~ms}$ after the $\mathbf{J}$ point) and/or a reversible perfusion defect on a myocardial single photon emission tomograph (SPECT). Furthermore, all patients had completely normal coronary angiograms (CAGs). This was independently confirmed by two cardiologists in separate viewing sessions and without clinical information.

The patients' characteristics are given in Table 1. None of the patients had a percutaneous transluminal coronary angioplasty (PTCA); coronary artery bypass grafting (CABG) or prior myocardial infarction; coronary spasm during the coronary angiography; absence of pain without medication; pregnancy; hypertension (defined as blood pressure over 140/ $90 \mathrm{mmHg}$ ); diabetes (defined by a fasting glucose level above $7.8 \mathrm{mmol}$ per liter or a random-sample glucose level above $11.1 \mathrm{mmol}$ per liter); arrhythmias such as paroxysmal atrial fibrillation (PAF); left bundle branch block; valve dysfunction

Table 1. Patient's characteristics

\begin{tabular}{ll}
\hline \multicolumn{1}{c}{ Patient's characteristics } & Value \\
\hline Age, mean \pm SD (years) & $55 \pm 11$ \\
Women, $\mathrm{n}(\%)$ & $14(70 \%)$ \\
Smoker, $\mathrm{n}(\%)$ & $3(15 \%)$ \\
Hypertension & $0(0 \%)$ \\
CAD in family & $13(65 \%)$ \\
Hyperventilation & $1(5 \%)$ \\
$\begin{array}{l}\text { Time between onset angina and first visit } \\
\text { cardiologist, mean } \pm \text { SD (years) }\end{array}$ & $3.1 \pm 8.1$ \\
$\begin{array}{l}\text { Number of coronary angiograms, mean } \\
\pm S D\end{array}$ & $1.2 \pm 0.5$ \\
$\begin{array}{l}\text { Number of patients using cardiac drugs } \\
\text { Number of patients restricted in daily living } \\
\quad \text { due to angina pectoris }\end{array}$ & $8(30 \%)$ \\
$\begin{array}{l}\text { Number of patients restricted in sport due } \\
\text { to chest pain }\end{array}$ & $5(25 \%)$ \\
$\begin{array}{l}\text { Number of patients experiencing chest } \\
\text { pain during emotional stress }\end{array}$ & $7(35 \%)$ \\
\hline
\end{tabular}

(other than mitral valve insufficiency grade 1); abnormal left ventricle ejection fraction (LVEF $<50 \%)$, or other structural abnormalities of the heart. Also, none of the patients had electrographic signs of left ventricular hypertrophy (defined as a value above $35 \mathrm{~mm}$ for the sum of the height of the $S$ wave in lead $\mathrm{V}_{1}$ and the height of the $\mathrm{R}$ wave in lead $\mathrm{V}_{5}$ ), ${ }^{28}$ or any change in clinical condition between the investigations.

The study complied with the Declaration of Helsinki, the institutional ethics committee approved this study, and all patients gave written informed consent.

\section{Screening for Anxiety}

Patients were recruited for a questionnaire study after their visit to the outpatient clinic of the cardiology department. State anxiety was measured by the State Scale (SS) and trait anxiety by the Trait Scale (TS) of the State-Trait Anxiety Inventory (STAI Dutch version revised by van der Ploeg, Defares, and Spielberger). ${ }^{29,30}$ This self-report scale measures the current symptoms of anxiety (state scale) and the participants' predisposition to anxiety (trait scale). It consists of $2 \times 20$ self-report items, and earlier use has shown good internal consistency $(\alpha=0.87-0.92)$ and validity. For analysis, the subjects were categorized as having low $($ score $<40$ ) or high (score $>40$ ) state and trait anxiety. ${ }^{31,32}$

For all the patients, the questionnaires were supplemented by reviews of medical records and by a general questionnaire, including indices of socio-economic status (education, marital status, and current employment).

\section{Myocardial Perfusion SPECT (Stress-Rest 2 Days Protocol)}

The first day was allocated to the stress (exercise) study. Patients were instructed to stop all cardiac medication 24 hours before testing, and to have a light breakfast. They had not consumed caffeine-containing beverages for 24 hours before the test. An intravenous line of normal saline solution, with a 20 -gauge cannula, was positioned in an antecubal vein. The exercise was performed on a calibrated ergometer using a symptom-limited test with stepwise increased work. A 12-lead electrocardiogram and blood pressure were monitored throughout the study. SPECT imaging was performed 4560 minutes after peak exercise radiotracer injection.

On day 2 the patients underwent an at-rest study. Acquisition parameters were identical to those for the stress study.

SPECT imaging was performed on a double-headed gamma camera with a high-resolution collimator. A symmetric $20 \%$ window was centered at $140 \mathrm{KeV}$, with a three-lead electric cardiographic monitoring. Imaging was acquired into a $64 \times 64$ computer matrix through a $180^{\circ}$ rotation, with 32 positions; starting position is RAO $45^{\circ}$, with 8 frames per cycle. Bull's-eye generation, and visual analysis using a 19segmental model were performed.

Three experienced observers interpreted the SPECT results. Perfusion was graded on a scale of $0-4$, with 0 representing normal perfusion and 4 representing a very severe 
perfusion defect. Perfusion defects graded one or more points below the at-rest SPECT results were considered to be ischemic. Consensus was obtained in cases of disagreement. Also, the observers had not been informed of the STAI results.

\section{Statistical Analysis}

Variables like the STAI trait and state score, and the number of reversible segments in the SPECT study were expressed as mean \pm standard deviation (SD). The numbers of patients (n) are expressed as absolute values and percentages of total $(\%)$. Variables were contrasted between two groups of low or high anxiety using an unpaired student test (two-sided), for both the state and the trait STAI groups. A $P$ value less than .05 was considered to be significant.

\section{RESULTS}

Table 2 lists the state anxiety and trait anxiety scores and the locations of ischemia on SPECT for all the patients.

\section{State STAI}

Six (6) patients had high state anxiety levels. These patients had a mean of $3.0 \pm 1.6$ reversible perfusion defects on SPECT. This value was not significantly different from the mean of $2.0 \pm 2.0$ reversible perfusion defects for patients with low state anxiety levels.

\section{Trait STAI}

Six (6) patients had a high trait anxiety score, reflecting a high predisposition to anxiety. These patients had a mean of $3.5 \pm 0.6$ reversible perfusion defects on SPECT. This value was significantly different $(P<.05)$ from the mean of $1.8 \pm 1.9$ reversible perfusion defects for patients with low trait anxiety scores. Figure 1 illustrates this difference.

\section{Cross-Sectional Comparisons between those with High or Low Trait Anxiety Scores}

Table 3 compares the patients with high and low scores for trait anxiety on the basis of demographic and medical variables. There is a trend for high trait anxiety patients to have more frequent chest pain during emotional stress, and they were also more frequently restricted in daily living as well as in practicing sports. However, none of the differences were statistically significant.

Table 2. Anxiety scores and location of ischemia for individual patients

\begin{tabular}{|c|c|c|c|c|}
\hline Patients & $\begin{array}{l}\text { State } \\
\text { anxiety }\end{array}$ & $\begin{array}{c}\text { Trait } \\
\text { anxiety }\end{array}$ & $\begin{array}{c}\text { Number of ischemic } \\
\text { segments }\end{array}$ & Location of ischemia \\
\hline 1 & 53 & 52 & 3 & Anterior (m), apical \\
\hline 2 & 34 & 36 & 1 & Anterior (b) \\
\hline 3 & 20 & 20 & 4 & Posterolat $(b)$, inferoseptal $(b+m)$, inferior $(m)$ \\
\hline 4 & 27 & 24 & 0 & \\
\hline 5 & 41 & 40 & 0 & \\
\hline 6 & 51 & 56 & 4 & Anterior $(\mathrm{d})$, posterolat $(\mathrm{b}+\mathrm{m}+\mathrm{d})$ \\
\hline 7 & 22 & 23 & 5 & Anterolat $(b+m)$, anteroseptal $(b+m+d)$ \\
\hline 8 & 31 & 44 & 3 & Inferior (b), anterolat (b), apical \\
\hline 9 & 52 & 58 & 3 & Inferior $(b+m)$, posterolat $(b+m)$ \\
\hline 10 & 39 & 36 & 5 & Inferior $(b+m)$, posterolat $(b+m)$ \\
\hline 11 & 24 & 26 & 0 & \\
\hline 12 & 33 & 36 & 0 & \\
\hline 13 & 39 & 34 & 2 & Inferior (b), posterolat (b) \\
\hline 14 & 36 & 29 & 1 & Anteroseptal (b) \\
\hline 15 & 41 & 44 & 4 & Anterior $(b+m+d)$, anteroseptal $(d)$ \\
\hline 16 & 38 & 38 & 4 & Anterior $(b+m)$, apical, anterolat $(d)$ \\
\hline 17 & 25 & 22 & 1 & Inferior (b) \\
\hline 18 & 51 & 56 & 4 & Posterolat $(b)$, inferior $(b+m)$, apical \\
\hline 19 & 24 & 24 & 0 & \\
\hline 20 & 36 & 39 & 2 & Anteroseptal $(\mathrm{m}+\mathrm{d})$ \\
\hline
\end{tabular}

State anxiety is considered increased with scores $>40$.

Trait anxiety is considered increased with scores $>40$.

$B$ basal, $m$ mid, $d$ distal segment. 


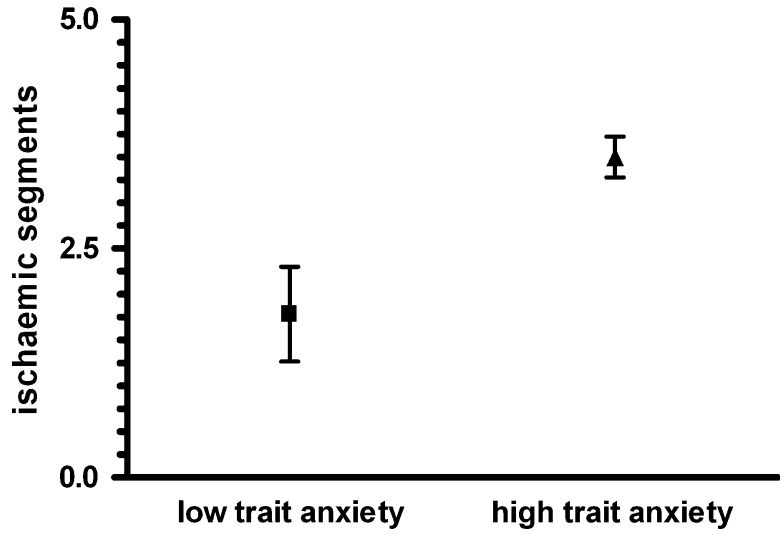

Figure 1. Patients with a high trait anxiety had significant more ischemic segments on SPECT. Mean values \pm SEM.

\section{DISCUSSION}

This study demonstrates the association between high trait anxiety and the extent of ischemia in CSX patients. This suggests that trait anxiety is associated with an increased risk of exercise-induced ischemia and that high trait anxiety might be a predisposing risk factor for cardiovascular damage causing reversible perfusion defects on the SPECT imaging of CSX patients.

As mentioned in the introduction to this paper, attention has recently been paid to the effect of psychological factors on coronary artery disease and cardiac neural mechanisms. ${ }^{23}$ Previous work identified the importance of impaired myocardial blood flow, particularly in the microvascular bed, in relation to ischemia induced by mental stress, ${ }^{24,25}$ and the phenomenon of endothelial dysfunction induced by mental stress has been described in CSX. ${ }^{26}$ Sudden emotional stress can lead to myocardial stunning in healthy subjects without CAD, probably owing to exaggerated sympathetic stimulation that causes vasoconstriction. ${ }^{33}$ Similarly, increased sympathetic tone from mental stress can cause vasoconstriction in patients without coronary disease, such as in CSX. . $^{33,34}$

The association between endothelial dysfunction and mental stress in CSX is reported in a SPECT study by Peix et al. ${ }^{26}$ CSX patients were asked to focus on an incident in their lives that made them very angry, and SPECT imaging was done during this period of mental stress. A total of 6 out of 16 patients had SPECT-imaged reversible perfusion defects, and this correlated with more frequent endothelial dysfunction measured by brachial artery flow-mediated dilation.

A limitation of the study by Peix et $\mathrm{al}^{26}$ is the nonstandard mental stress test, since it cannot be assumed that the subjects were exposed to similar levels of mental stress. We have attempted in our pilot study to avoid this limitation by using validated standardized questionnaires for anxiety disorders to measure the anxiety predispositions and levels of each CSX patient. As mentioned earlier, state anxiety was measured by the State Scale (SS) and trait anxiety by the Trait Scale (TS) of the StateTrait Anxiety Inventory (STAI Dutch version revised by van der Ploeg, Defares, and Spielberger). ${ }^{29,30}$

Interestingly, a recent study of CAD patients showed that mental stress provokes a different myocardial ischemic response compared to exercise or adenosine ${ }^{35}$ However, there is a little data available for patients groups with normal coronary arteries or syndrome X.

There are limited previous data on anxiety disorder and its relation to endothelial dysfunction. Narita et $\mathrm{al}^{36}$ used brachial artery flow measurements to investigate anxiety levels and endothelial dysfunction in elderly males. They found no link between high state anxiety levels and endothelial dysfunction, but there was a link for high trait anxiety. This result is broadly similar to that of our study, in which we showed that CSX patients

Table 3. Characteristics of patients with high versus low trait anxiety

\begin{tabular}{lccc}
\hline \multicolumn{1}{c}{ Patient's characteristics } & $\begin{array}{c}\text { High trait } \\
\text { anxiety (n = 6) }\end{array}$ & $\begin{array}{c}\text { Low trait anxiety } \\
(\mathbf{n}=\mathbf{1 4})\end{array}$ & $\begin{array}{c}\boldsymbol{P} \\
\text { value }\end{array}$ \\
\hline Age, mean \pm SD (years) & $55 \pm 15$ & $55 \pm 9$ & $\mathrm{NS}$ \\
Woman, \% & 67 & 65 & $\mathrm{NS}$ \\
Smoker, \% & 17 & 14 & $\mathrm{NS}$ \\
CAD in family, \% & 33 & 78 & $\mathrm{NS}$ \\
Time between onset angina and first visit cardiologist, & $2.2 \pm 3.9$ & $3.2 \pm 9.1$ & $\mathrm{NS}$ \\
$\quad$ mean \pm SD (years) & & & $\mathrm{NS}$ \\
Cardiac drugs, \% & 33 & 43 & $\mathrm{NS}$ \\
Restricted in daily living due to angina pectoris, \% & 50 & 21 & $\mathrm{NS}$ \\
Restricted in sport due to chest pain, \% & 33 & 21 & $\mathrm{NS}$ \\
Chest pain during emotional stress, \% & 67 & 21 & \\
\hline
\end{tabular}


with high trait anxiety are at risk of having more extended ischemia compared to CSX patients with low trait anxiety.

\section{Reasons for Differences in the State and Trait Anxiety Results}

(1) In our study, the lack of significance in the extent of ischemia between CSX patients with high and low state anxiety levels could have two reasons: firstly the small population of 20 patients, and secondly the time delay between state anxiety measurements and SPECT scanning. This latter possibility is because state anxiety levels may differ at different times. Obviously, a more definitive study involving a larger population is needed, whereby myocardial ischemia is investigated for state and trait anxiety levels at one time.

(2) A pathophysiological explanation for the different findings between the state and trait anxiety levels may be the different effects they have on the development of ischemia. State anxiety reflects a transitory emotional condition characterized by subjective feelings of tension, and is associated with heightened autonomic nervous system activity. Trait anxiety, on the other hand, reflects the existence of a certain predisposition to anxiety. A high predisposition to anxiety could reflect a chronic stress condition with long-term high anxiety levels. In turn, high anxiety levels are most probably a risk factor for cardiovascular damage only when they are sustained for long periods.

This hypothesis may also help to explain the results of Narita et $\mathrm{al},{ }^{36}$ in particular their result that there was a significant association between trait anxiety and endothelial dysfunction for elderly males but not for young ones.

\section{CONCLUSION}

This pilot study showed that CSX patients with high trait anxiety are at risk of having more extended ischemia compared to CSX patients with low trait anxiety. This suggests that anxiety-induced ischemia can occur in CSX patients, and that high trait anxiety might be a predisposing risk factor for cardiovascular damage causing reversible perfusion defects on the SPECT imaging of CSX patients.

\section{Acknowledgment}

We thank Dr R.J.H. Wanhill for his critical review and editing of the manuscript.
Open Access This article is distributed under the terms of the Creative Commons Attribution Noncommercial License which permits any noncommercial use, distribution, and reproduction in any medium, provided the original author(s) and source are credited.

\section{References}

1. Bottcher M, Botker HE, Sonne H, Nielsen TT, Czernin J. Endothelium-dependent and -independent perfusion reserve and the effect of L-arginine on myocardial perfusion in patients with syndrome X. Circulation 1999;99:1795-801.

2. Panza JA. Myocardial ischemia and the pains of the heart. N Engl J Med 2002;346:1934-5.

3. Kemp HG Jr, Vokonas PS, Cohn PF, Gorlin R. The anginal syndrome associated with normal coronary arteriograms. Report of a six year experience. Am J Med 1973;54:735-42.

4. Likoff W, Segal BL, Kasparian H. Paradox of normal selective coronary arteriograms in patients considered to have unmistakable coronary heart disease. N Engl J Med 1967;276:1063-6.

5. Fragasso G, Rossetti E, Dosio F, Gianolli L, Pizzetti G, Cattaneo $\mathrm{N}$, et al. High prevalence of the thallium-201 reverse redistribution phenomenon in patients with syndrome X. Eur Heart $\mathrm{J}$ 1996; 17:1482-7.

6. Hsu HB, Shiau YC, Kao A, Lin CC, Lee CC. Technetium- 99 m tetrofosmin myocardial perfusion single photon emission computed tomography in syndrome X: A preliminary report. Jpn Heart J 2003;44:153-62.

7. Kao CH, Wang SJ, Ting CT, Chen YT. Thallium-201 myocardial SPET in strictly defined syndrome $\mathrm{X}$. Nucl Med Commun 1995; 16:640-6.

8. Kao CH, Wang SJ, Ting CT, Chen YT. Tc-99 m sestamibi myocardial SPECT in syndrome X. Clin Nucl Med 1996;21:280-3.

9. Tweddel AC, Martin W, Hutton I. Thallium scans in syndrome X. Br Heart J 1992;68:48-50.

10. Rosen SD, Camici PG. Syndrome X: Background, clinical aspects, pathophysiology and treatment. G Ital Cardiol 1994;24:779-90.

11. Cox ID, Botker HE, Bagger JP, Sonne HS, Kristensen BO, Kaski JC. Elevated endothelin concentrations are associated with reduced coronary vasomotor responses in patients with chest pain and normal coronary arteriograms. J Am Coll Cardiol 1999;34:455-60.

12. Buchthal SD, den Hollander JA, Merz CN, Rogers WJ, Pepine CJ, Reichek N, et al. Abnormal myocardial phosphorus-31 nuclear magnetic resonance spectroscopy in women with chest pain but normal coronary angiograms. N Engl J Med 2000;342:829-35.

13. Motz W, Vogt M, Rabenau O, Scheler S, Luckhoff A, Strauer BE. Evidence of endothelial dysfunction in coronary resistance vessels in patients with angina pectoris and normal coronary angiograms 28. Am J Cardiol 1991;68:996-1003.

14. Egashira K, Inou T, Hirooka Y, Yamada A, Urabe Y, Takeshita A. Evidence of impaired endothelium-dependent coronary vasodilatation in patients with angina pectoris and normal coronary angiograms. N Engl J Med 1993;328:1659-64.

15. Lanza GA, Luscher TF, Pasceri V, Shaw SG, Buffon A, Montenero AS, et al. Effects of atrial pacing on arterial and coronary sinus endothelin-1 levels in syndrome X29. Am J Cardiol 1999;84:1187-91.

16. Lanza GA, Buffon A, Sestito A, Natale L, Sgueglia GA, Galiuto L, et al. Relation between stress-induced myocardial perfusion defects on cardiovascular magnetic resonance and coronary 
microvascular dysfunction in patients with cardiac syndrome X. J Am Coll Cardiol 2008;51:466-72.

17. Panting JR, Gatehouse PD, Yang GZ, Grothues F, Firmin DN, Collins $\mathrm{P}$, et al. Abnormal subendocardial perfusion in cardiac syndrome $\mathrm{X}$ detected by cardiovascular magnetic resonance imaging. N Engl J Med 2002;346:1948-53.

18. de Vries J, DeJongste MJ, Jessurun GA, Jager PL, Staal MJ, Slart RH. Myocardial perfusion quantification in patients suspected of cardiac syndrome $\mathrm{X}$ with positive and negative exercise testing: A [13N]ammonia positron emission tomography study. Nucl Med Commun 2006;27:791-4.

19. Graf S, Khorsand A, Gwechenberger M, Schutz M, Kletter K, Sochor $\mathrm{H}$, et al. Myocardial perfusion in patients with typical chest pain and normal angiogram. Eur J Clin Invest 2006;36:326-32.

20. Graf S, Khorsand A, Gwechenberger M, Novotny C, Kletter K, Sochor $\mathrm{H}$, et al. Typical chest pain and normal coronary angiogram: Cardiac risk factor analysis versus PET for detection of microvascular disease. J Nucl Med 2007;48:175-81.

21. Vermeltfoort IA, Bondarenko O, Raijmakers PG, Odekerken DA, Kuijper AF, Zwijnenburg A, et al. Is subendocardial ischaemia present in patients with chest pain and normal coronary angiograms? A cardiovascular MR study. Eur Heart J 2007;28:1554-8.

22. Rosen SD, Uren NG, Kaski JC, Tousoulis D, Davies GJ, Camici PG. Coronary vasodilator reserve, pain perception, and sex in patients with syndrome X. Circulation 1994;90:50-60.

23. Burg MM, Vashist A, Soufer R. Mental stress ischemia: Present status and future goals. J Nucl Cardiol 2005;12:523-9.

24. Arrighi JA, Burg M, Cohen IS, Kao AH, Pfau S, Caulin-Glaser T, et al. Myocardial blood-flow response during mental stress in patients with coronary artery disease. Lancet 2000;356:310-1.

25. Yeung AC, Vekshtein VI, Krantz DS, Vita JA, Ryan TJ Jr, Ganz P, et al. The effect of atherosclerosis on the vasomotor response of coronary arteries to mental stress. N Engl J Med 1991;325:1551-6.

26. Peix A, Trapaga A, Asen L, Ponce F, Infante O, Valiente J, et al. Mental stress-induced myocardial ischemia in women with angina and normal coronary angiograms. J Nucl Cardiol 2006;13:507-13.
27. Asbury EA, Creed F, Collins P. Distinct psychosocial differences between women with coronary heart disease and cardiac syndrome X. Eur Heart J 2004;25:1695-701.

28. Zipes DP, Braunwald E. Braunwald's heart disease a textbook of cardiovascular medicine. Philadelphia, PA: Elsevier Saunders; 2005.

29. van den Broek KC, Denollet J, Nyklicek I, van der Voort PH. Psychological reaction to potential malfunctioning of implantable defibrillators. Pacing Clin Electrophysiol 2006;29:953-6.

30. Verkuil B, Brosschot JF, Thayer JF. Capturing worry in daily life: Are trait questionnaires sufficient? Behav Res Ther 2007;45: 1835-44.

31. Brans B, van den EF, Audenaert K, Vervaet M, van Daele K, van Heeringen $\mathrm{C}$, et al. Depression and anxiety during isolation and radionuclide therapy. Nucl Med Commun 2003;24:881-6.

32. Britton JR (2007) Maternal anxiety: Course and antecedents during the early postpartum period. Depress Anxiety 2007;25:793800 .

33. Wittstein IS, Thiemann DR, Lima JA, Baughman KL, Schulman SP, Gerstenblith G, et al. Neurohumoral features of myocardial stunning due to sudden emotional stress. N Engl J Med 2005;352:539-48.

34. Lacy CR, Contrada RJ, Robbins ML, Tannenbaum AK, Moreyra $\mathrm{AE}$, Chelton S, et al. Coronary vasoconstriction induced by mental stress (simulated public speaking). Am J Cardiol 1995;75:503-5.

35. Hassan M, York KM, Li Q, Lucey DG, Fillingim RB, Sheps DS. Variability of myocardial ischemic responses to mental versus exercise or adenosine stress in patients with coronary artery disease. J Nucl Cardiol 2008;15:518-25.

36. Narita K, Murata T, Hamada T, Takahashi T, Kosaka H, Yoshida $\mathrm{H}$, et al. Association between trait anxiety and endothelial function observed in elderly males but not in young males. Int Psychogeriatr 2007;19:947-54. 